\title{
The Importance of Auditory Evaluation in Adults between 45 and 65 Years 0ld
}

\author{
Loretta Fabianne Nigri ${ }^{1 *}$ and Maria Cecília Martinelli \\ ${ }^{1}$ Doctoral Student, Department of Audiology and Speech Science, Federal University of São Paulo, Brazil \\ ${ }^{2}$ Doctor, Department of Audiology and Speech Science, Federal University of São Paulo, Brazil
}

Submission: July 30, 2020; Published: August 19, 2020

*Corresponding author: Loretta Fabianne Nigri, Doctoral Student, department of audiology and speech science, Federal University of São Paulo, Brazil

\section{Abstract}

Hearing loss is a public health problem that affects the individual's communication that requires a multidisciplinary evaluation and an intervention as soon as possible to improve his/her quality of life.

\section{Introduction}

As the world's population increases in age, the number of people living with dementia grows, and this figure is projected to continue to rise, especially in low and middle-income countries [1]. In 2000, the Brazilian population over 60 was only $5 \%$; it is assumed that in 2050 it will be $18 \%$ [2]. Projections indicate that in 2025, it will occupy the $6^{\text {th }}$ place among the countries with the oldest in the world [3]. Around 47 million people were living with dementia worldwide in 2015, affecting the individual living with it, their family, as they become more dependent, and the wider society, which provides and often pays for care and support. The number of people with dementia is expected to increase to 66 million by 2030, and 131 million by 2050 [4], driven by rising numbers of older adults [5]. Thus, with the increase in life expectancy, there is a concern with the quality of life of the elderly population, creating new demands for specialized intervention, as is the case of Speech Therapy.

With aging, there is a decline in physiological and sensory functions. Among the sensory changes caused by advancing age, is presbycusis, hearing loss due to aging [6], which affects the peripheral auditory system, and leads to a decline in communication capacity, which leads the elderly to social isolation and deprivation of information sources and, consequently, to social and emotional changes. Hearing loss is the second most prevalent chronic disease and the third leading cause of disability $[7,8]$. This significant increase in hearing loss occurs in the elderly population, in which one in three adults over 65 years of age presents disabling hearing loss [9].
The risk of hearing loss for dementia in the meta-analysis of three studies [10-12], is not only higher than the risk from other individual risk factors, but it is also pertinent to many people because it is highly prevalent, occurring in $32 \%$ of individuals aged older than 55 years [13]. We have used the prevalence of hearing loss in individuals older than 55 years because this age was the youngest mean age in which presence of hearing loss was shown to increase dementia risk [12]. Hearing loss is therefore grouped with the midlife risk factors, but evidence suggests that it continues to increase dementia risk in later life.

Studies show that the prevalence of hearing loss in individuals diagnosed with dementia is higher than that observed in elderly people without dementia and it is believed that hearing loss prominently promotes dementia [11]. If there is a real causal relationship between hearing loss and MCI, it will provide insights for preventing dementia in clinical settings. The use of hearing aids seems to reduce adverse health outcomes due to loneliness, [14]. Another hypothesis is that hearing loss leads to social isolation, which has been shown to contribute to dementia $[15,16]$.

It is known that $65 \%$ of the risk for the development of dementias are not modifiable, among which we can mention the age. The older you are, the greater your risk of developing dementia. The $35 \%$ of modifiable factors include improving childhood education, physical exercise, maintaining social engagement, reducing, or quitting smoking, intervening in hearing loss, controlling depression, diabetes, hypertension, and obesity. Of these 35\%, 11\% refer to hearing loss that starts between 45 
and 65 years old. Therefore, we can control 11\% of the probability of the occurrence of dementia by interfering in hearing loss at the beginning between 45 and 65 years [17]. Thus, Prevention is better than cure and underlies the growing interest in modifiable risk factors. In published work on dementia risk, midlife has been defined as 45-65 years and later life as older than 65 years.

Among these, education, depression, social isolation, and hearing loss can be highlighted. In turn, social isolation can be observed in the hearing impaired, mainly the elderly, prior to the speech therapy intervention, through the fitting of hearing aids. There is a reversal of the picture when they become users of sound amplification devices. The treatment of hearing loss causes individuals to remain involved in social activities [18]. This benefit is not only seen by users, but also by family members, who are benefited, since family relationships seem to be more preserved.

As already explained, although the precise mechanisms by which hearing loss causes an adverse cognitive state are not clear, several potential mechanisms have been proposed. First, hearing deprivation can cause decreased socialization and increased depression, as well as a decline in cognitive function, which can result in CCL or dementia [16]. In addition, it is possible that hearing loss causes cognitive resources, operational memory, to operate with greater demand to process altered sound information, which creates an excessive cognitive load on upper cortical functions, leading to cognitive decline and dementia [19]. Hearing impairment can also modify the auditory pathway and the brain, which causes cognitive decline and dementia [20].

Alternatively, studies suggest that hearing impairment and cognitive decline share a common neurodegenerative process, which leads to both hearing loss and CCL / dementia [21]. Studies have shown that hearing loss precedes the occurrence of MCI and dementia, and there are studies that have shown that the use of hearing aids is associated with better cognition, regardless of social isolation and depression. Improving the hearing capacity of the entire population can fundamentally reduce the prevalence of hearing loss and reduces the risk of dementia. The implementation of the population strategy, however, is challenging, since public awareness of hearing loss as an important risk factor for MCI and dementia is low among the elderly compared to others, such as physical activity [22]. Several studies have investigated the impact of hearing aid use on cognition [10,11,14,20,23-25].

The main purpose of preclinical detection of Alzheimer's disease is to identify individuals at high risk of progression to dementia due to Alzheimer's disease, so that they can have the opportunity to participate in treatment trials to delay or prevent cognitive decline. These individuals can also be informed and make changes in their lifestyle, which might delay onset of dementia. Some people might also find prognostic information to be useful because it allows them to make plans and lifestyle changes for a possible future dementia.

\section{Conclusion}

Meta-analysis studies have shown that hearing loss is associated with an increased risk of MCI and dementia among the elderly. Future intervention studies are needed to assess whether treatment of hearing loss can reduce the risk of MCI and dementia in older adults. Measures should also be taken to improve hearing ability among the elderly to further prevent MCI and dementia. Continued progress will build on what has long informed dementia care: to prevent the preventable, treat the treatable, and care for both the person living with dementia and the career. The recommendations are informed by the knowledge that dementia impairs cognition and therefore challenges the ability of people to make decisions for themselves, understand, and communicate what they want and need. Additionally, giving people information about how to prevent or treat dementia is an essential first step, but is not enough. There is a responsibility, not just as professionals but as a society, to implement this evidence into early interventions that are widely and effectively used for people with dementia and their families. Interventions must be accessible, sustainable, and, if possible, enjoyable or they will be unused. Delivery of interventions will vary according to the health system, with some countries having free health care at the point of delivery for all and other countries having to implement this care as part of a program. Thus, while it is recommended specific interventions to prevent dementia, diagnose it early, manage the cognitive and neuropsychiatric symptoms, support careers, and improve living and dying with dementia, it is important that this health and social care occurs within, rather than separate from, society, so it can become truly dementia friendly.

\section{References}

1. Alzheimer's Disease International (2013) The global impact of dementia 2013-2050: policy brief for heads of Government. Alzheimer's Disease International, London.

2. IBGE (2017) Projeção da população do Brasil e das Unidades da Federação, Brazil.

3. Organização Mundial da Saúde (OMS) (1996) CID-10: Classificação estatística internacional de doenças e problemas relacionados à Saúde ( $3^{\text {rd }}$ Ed) São Paulo, EDUSP, p. 1200.

4. Prince M, Wimo A, Guerchet M, Ali GC, Wu YT, et al. (2015) The global impact of dementia: an analysis of prevalence, incidence, cost and trends.Alzheimer's Disease International, London.

5. Jones L, Candy B, Davis S, Margaret Elliott, Anna Gola, et al. (2016) Development of a model for integrated care at the end of life in advanced dementia: a whole systems UK-wide approach. Palliat Med 30: 279-295.

6. Rosenhall U, Pedersen K, Svanborg A (1990) Presbycusis and noiseinduced hearing loss. Ear Hear 11: 257-263.

7. Vos T, Allen C, Arora M, Barber RM, Bhutta ZA, et al. (2016) Global, regional, and national incidence, prevalence, and years lived with disability for 310 diseases and injuries, 1990-2015: a systematic analysis for the Global Burden of Disease Study 2015. Lancet 388(10053): 1545-1602. 
8. Vos T, Abajobir AA, Abate KH, Abbafati C, Abbas KM, et al. (2017) Global, regional, and national incidence, prevalence, and years lived with disability for 328 diseases and injuries for 195 countries, 19902016: a systematic analysis for the Global Burden of Disease Study 2016. Lancet 390(10100): 1211-1259.

9. World Health Organization. Deafness and hearing impairment (2018) Geneva: World Health Organization.

10. Deal JA, Betz J, Yaffe K, Tamara Harris, Elizabeth Purchase Helzner, et al. (2016) Hearing impairment and incident dementia and cognitive decline in older adults: The Health ABC Study. J Gerontol A Biol Sci Med Sci 72(5): 703-709.

11. Lin FR, Metter EJ, O Brien RJ, Resnick SM, Zonderman AB, et al. (2011) Hearing loss and incident dementia. Arch Neurol 68: 214-220.

12. Gallacher J, Ilubaera V, Ben Shlomo Y, Antony Bayer, Mark Fish, et al. (2012) Auditory threshold, phonologic demand, and incident dementia. Neurology 79: 1583-1590.

13. Scholes S, Mindell J (2014) Health Survey for England (2014): health, social care, and lifestyles. Craig R Fuller E Mindell J (Eds) Chapter 4: Hearing, Health and Social Care Information Centre, London.

14. Weinstein BE, Sirow LW, Moser S (2016) Relating hearing aid use to social and emotional loneliness in older adults. Am J Audiol 25: 54-61.

15. Shankar A, Hamer M, McMunn A, Steptoe A (2013) Social isolation and loneliness: relationships with cognitive function during 4 years of follow-up in the English Longitudinal Study of Ageing. Psychosom Med 75: 161-170.

16. Mick P, Kawachi I, Lin FR (2014) The association between hearing loss and social isolation in older adults. Otolaryngol Head Neck Surg 150: 378-384.
17. Rachael Davies (2017) Livingston G: transforming dementia prevention and care. Lancet 390 (10113) :2619.

18. Capella McDonall (2005) The effects of single and dual sensory loss on symptoms of depression in the elderly. Int J Geriatr Psychiatry 9: 855-861.

19. Pichora Fuller MK, Kramer SE, Eckert MA, Edwards B, Hornsby BW, et al. (2016) Hearing impairment and cognitive energy: The Framework for Understanding Effortful Listening (FUEL). Ear Hear 37(suppl 1): $5 s-27 s$.

20. Lin FR, Ferrucci L, An Y, Goh JO, Doshi J, et al. (2014) Association of hearing impairment with brain volume changes in older adults. Neuroimage $90: 84-92$.

21. Davis A, McMahon CM, Pichora Fuller KM, Russ S, Lin F, et al. (2016) Aging and hearing health: the life-course approach. Gerontologist 56(suppl 2): S256-S267.

22. Lin FR, Albert M (2014) Hearing loss and dementia - who is listening? Aging Ment Health 18: 671-673.

23. Lin MY, Gutierrez PR, Stone KL, Kristine Yaffe, Kristine E Ensrud, et al. (2004) Vision impairment and combined vision and hearing impairment predict cognitive and functional decline in older women. J Am Geriatr Soc 52: 1996-2002.

24. Lin FR, Yaffe K, Xia J, Qian Li Xue, Tamara B Harris, et al. (2013) Hearing loss and cognitive decline in older adults. JAMA Intern Med 173: 293 299.

25. Amieva H, Ouvrard C, Giulioli C, Meillon C, Rullier L, et al. (2015) Selfreported hearing loss, hearing aids, and cognitive decline in elderly adults: a 25-year study. J Am Geriatr Soc 63: 2099-2104.

\section{Your next submission with Juniper Publishers will reach you the below assets}

- Quality Editorial service

- Swift Peer Review

- Reprints availability

- E-prints Service

- Manuscript Podcast for convenient understanding

- Global attainment for your research

- Manuscript accessibility in different formats

( Pdf, E-pub, Full Text, Audio)

- Unceasing customer service

Track the below URL for one-step submission https://juniperpublishers.com/online-submission.php 